\title{
A functional alternative splicing mutation in human tryptophan hydroxylase-2
}

\author{
X Zhang ${ }^{1,2,3}$, PJ Nicholls ${ }^{2}$, G Laje $^{4}$, TD Sotnikova ${ }^{1,5}$, RR Gainetdinov ${ }^{1,5}$, PR Albert ${ }^{6}$, G Rajkowska ${ }^{7}$, \\ CA Stockmeier 7,8 , MC Speer ${ }^{9}$, DC Steffens ${ }^{2}$, MC Austin7, FJ McMahon ${ }^{4}$, KRR Krishnan², \\ MA Garcia-Blanco ${ }^{10}$ and MG Caron ${ }^{1}$
}

\begin{abstract}
${ }^{1}$ Department of Cell Biology, Duke University Medical Center, Durham, NC, USA; ${ }^{2}$ Department of Psychiatry and Behavioral Sciences, Duke University Medical Center, Durham, NC, USA; ${ }^{3}$ Neuroscience \& Behavioral Disorders Program, Duke-National University of Singapore Graduate Medical School, Singapore, Singapore; ${ }^{4}$ Unit on Genetic Basis of Mood \& Anxiety Disorders, National Institute of Mental Health, NIH, Bethesda, MD, USA; ${ }^{5}$ Department of Neuroscience, Italian Institute of Technology, Genova, Italy; ${ }^{6} \mathrm{OHRI}$ (Neuroscience), University of Ottawa, Ottawa, ON, Canada; ${ }^{7}$ Department of Psychiatry and Human Behavior, University of Mississippi Medical Center, Jackson, MS, USA; ${ }^{8}$ Department of Psychiatry, Case Western Reserve University, Cleveland, OH, USA; ${ }^{9}$ Center for Human Genetics, Duke University Medical Center, Durham, NC, USA and ${ }^{10}$ Department of Molecular Genetics and Microbiology, Duke University Medical Center, Durham, NC, USA
\end{abstract}

\begin{abstract}
The brain serotonergic system has an essential role in the physiological functions of the central nervous system and dysregulation of serotonin (5-HT) homeostasis has been implicated in many neuropsychiatric disorders. The tryptophan hydroxylase-2 (TPH2) gene is the rate-limiting enzyme in brain 5-HT synthesis, and thus is an ideal candidate gene for understanding the role of dysregulation of brain serotonergic homeostasis. Here, we characterized a common, but functional single-nucleotide polymorphism (SNP rs1386493) in the TPH2 gene, which decreases efficiency of normal RNA splicing, resulting in a truncated TPH2 protein (TPH2-TR) by alternative splicing. TPH2-TR, which lacks TPH2 enzyme activity, dominant-negatively affects full-length TPH2 function, causing reduced 5-HT production. The predicted mRNA for TPH2-TR is present in postmortem brain of rs 1386493 carriers. The rs13864923 variant does not appear to be overrepresented in either global or multiplex depression cohorts. However, in combination with other gene variants linked to 5-HT homeostasis, this variant may exhibit important epistatic influences.

Molecular Psychiatry (2011) 16, 1169-1176; doi:10.1038/mp.2010.99; published online 21 September 2010
\end{abstract}

Keywords: TPH2; serotonin (5-HT); SNP; alternative splicing

\section{Introduction}

Dysregulation of the brain serotonergic (5-HT) system has been implicated in disorders such as major depression, ${ }^{1}$ attention-deficit/hyperactivity disorder, ${ }^{2}$ schizophrenia, ${ }^{3}$ aggression and suicidal behavior. ${ }^{4}$ Among the genes involved in the brain 5-HT system, the 5-HT transporter, especially its functional polymorphism in the promoter region, has been well characterized for its association with anxiety and depression. $^{5,6}$ Tryptophan hydroxylase-1 (TPH1) gene was long considered the only rate-limiting enzyme in 5-HT synthesis, and its potential association with various neuropsychiatric disorders has been widely explored, but not without controversies. ${ }^{4}$ However, a second gene (TPH2) has been recently discovered as a

Correspondence: Dr X Zhang, Neuroscience \& Behavioral Disorders Program, Duke-National University of Singapore Graduate Medical School, Singapore 169857 or Professor MG Caron, Department of Cell Biology, 487 CARL Building, Box 3287, Duke University Medical Center Durham, NC 27710, USA.

E-mail: xiaodong.zhang@duke-nus.edu.sg or m.caron@cellbio.duke.edu Received 15 February 2010; revised 5 August 2010; accepted 8 August 2010; published online 21 September 2010 neuronal-specific gene ${ }^{7}$ that controls brain 5 -HT synthesis, ${ }^{8}$ whereas the previously known TPH1 gene is essential for peripheral 5-HT synthesis. ${ }^{7}$ Since its discovery in $2003,{ }^{7}$ the TPH2 gene has been extensively studied for its association with various neuropsychiatric disorders, yielding over 500 genetic variants in human. Except for a few examples of functional characterization, ${ }^{9-12}$ the majority of human TPH2 genetic variants that have been found in the introns, untranslated regions and promoter regions, remain to be physiologically characterized. ${ }^{13}$

In this study, we developed a functional approach to characterize an intronic single-nucleotide polymorphism (SNP rs1386493) that was previously identified in cohorts of neuropsychiatric disorders and controls. ${ }^{14,15}$ We used a minigene construct carrying a partial TPH2 genomic DNA sequence to address the physiological consequence of this SNP. Our data indicate that SNP (rs1386493) reduces normal splicing of intron 5 by generating an alternatively spliced transcript Q8N1X9 that can be detected in postmortem brainstem tissues. The truncated protein of Q8N1X9 is devoid of TPH2 enzyme activity, and exerts a dominant-negative effect in vitro 
on the ability of the normal Tph2 enzyme to support 5-HT synthesis. Although the allele frequency of this SNP is not significantly different in cohorts we have analyzed so far, our data provide a novel mechanism that could regulate brain 5-HT synthesis and suggest that genetic variations in the TPH2 gene could contribute to the etiology of conditions associated with dysfunction of the 5-HT system. Moreover, homozygous carriers of this SNP were identified in a subset of multiplex Caucasian families from the NIMH Depression Pedigree. Therefore, our data suggest that mutations in the TPH2 gene could be one of the many contributing risk factors for major depression.

\section{Materials and methods}

IRB approval

The use of human genomic DNA samples and human brainstem tissues was approved by Duke University Medical Center Institutional Review Board. Brain samples from human dorsal raphe were obtained at autopsy at the Coroner's Office of Cuyahoga County, Cleveland, $\mathrm{OH}$, USA. The study was performed using a protocol approved by the Institutional Review Boards of University Hospitals of Cleveland and the University of Mississippi Medical Center. Informed consent was obtained from the legally determined next-of-kin for all subjects.

Genotyping for SNP (rs1386493) by restriction fragment length polymorphism

Genomic DNA (10 ng) was amplified by PCR using forward primer (5'-TACCTTGTACTGATGTGTATTGG TCAAGAGT) and reverse primer (5'-TTGCACACATG AATTTTCGTAAATGAGTCTA) to obtain an $889 \mathrm{bp}$ fragment. The PCR fragment was digested with restriction enzyme, Ava II (NEB, Ipswich, MA, USA), which cut G-allele (GGACC) into two fragments of 605 and $284 \mathrm{bp}$. A-allele (․GACC) containing fragment was not cut by Ava II.

\section{PCR amplification}

Human TPH2 genomic DNA from bacterial artificial chromosome clone RP11-89M22 (BACPAC Resource Center, Oakland, CA, USA) was amplified using EXL DNA polymerase (Stratagene, La Jolla, CA, USA). Taq DNA polymerase (Fisher, Pittsburgh, PA, USA) was used for genotyping and PCR amplification following RT-PCR. The nested PCR was conducted by 20 cycles of amplification using the first set of primers, followed by 40 cycles of amplification using the second set of primers and a diluted PCR solution from the first PCR as template.

\section{$R T-P C R$ and real-time $R T-P C R$ analyses}

Total RNA from PC12 cells stably transfected with minigene constructs and human brainstem tissues was prepared using TRI Reagent RNA Isolation Reagent (Sigma, St Louis, MO, USA). Total RNA was then treated with DNase I (Sigma). ProtoScript First Strand cDNA Synthesis Kit (NEB) was then used to obtain cDNA from total RNA or an Intron 5 specific sequence (5'-TTTTTTCTAATTTTCTCAATTCAGTTTT) was used for detecting alternative splicing transcript in PC12 cells (Figures 2c and e). Real-time RT-PCR was performed using Platinum ${ }^{\circledR}$ SYBR $^{\circledR}$ Green qPCR SuperMix-UDG (Invitrogen, Carlsbad, CA, USA) with the following conditions: denaturated at $95{ }^{\circ} \mathrm{C}$ for $3 \mathrm{~min}$ followed by 40 cycles of amplification at $95^{\circ} \mathrm{C}$ for $2 \mathrm{~s}, 60^{\circ} \mathrm{C}$ for $20 \mathrm{~s}$ and $72{ }^{\circ} \mathrm{C}$ for $30 \mathrm{~s}$. Gene expression was normalized to neomycin-resistance gene $\left(\mathrm{Neo}^{\mathrm{R}}\right)$.

\section{PC12 cell lines and 5-HT detection}

PC12 cell lines were maintained in DMEM media with $5 \%$ iron-supplemented bovine calf serum (HyClone, Logan, UT, USA) and 5\% equine serum (HyClone), and $10 \% \mathrm{CO}_{2}$. PC12 cells were transfected by electroporation (Bio-Rad, Hercules, CA, USA) as previously described..$^{8,9}$ The production of 5-HT was analyzed by HPLC using an electrochemical detector as described previously for the characterization of loss-of-function TPH2 mutants in mice and human. ${ }^{8,9}$ Western blotting was performed using anti-hemagglutinin (Covance, Princeton, NJ, USA) and anti-actin (Millipore, Billerica, MA, USA) monoclonal antibodies and goat anti-mouse secondary antibody conjugated with horseradish peroxidase (Pierce, Rockford, IL, USA).

\section{Primer information \\ P1 (5'-AGTGTGCTGGAATTCGAGCTCACTCTCTT), P2 (5'-TAAGCTTAGGCTCTTGGCGTTCGGAGGAT), P3 (5'-ACCAGGGATTTAAGGACAATGTCTATCGA CAGAG), \\ P4 (5'-ACTCTCGGCAAGCATGAGTGGGATAG), P5 (5'-AGTCATCTGACATACGTGGCTTGACG), P6 (5'-TGCTGGAATTCGAGCTCACTCTCTTC), P7 (5'-GCACGCTCAACATACACAAGGAGC), P8 (5'-ATGCAGCCAGCAATGATGATGTTTTCCAG), P9 (5'-AGCAGTGCCCGAAGAGCATCAGC), P10 (5'-TTGCACACATGAATTTTCGTAAATGAGTCTA).}

RT-PCR for NeoR: $622 \mathrm{bp}$-F (5'-ATCAGAGCAGCCGATTGTCTGTTGT), 622 bp-R (5'-TACCCGTGATATTGCTGAAGAGCTT).

Real-time RT-PCR for NeoR: qPCR-F (5'-TCCTGTCATCTCACCTTGCTCCTGC), qPCR-R (5'-TGCTCTTCGTCCAGATCATCCTGATCG AC).

\section{RT-PCR for GAPDH:}

Forward (5'-TGC[A/C]TCCTGCACCACCAACT), Reverse (5'-[C/T]GCCTGCTTCACCACCTTC).

\section{URLS}

Ensembl: http://www.ensembl.org/index.html, National Center for Biotechnology Information (NCBI) database: http://www.ncbi.nlm.nih.gov, ESEfinder: http://rulai. cshl.edu/tools/ESE/.

\section{Results}

Truncated TPH2 gene

The full-length human TPH2 gene (Ensembl: ENST00000333850) possesses 11 exons and spans 


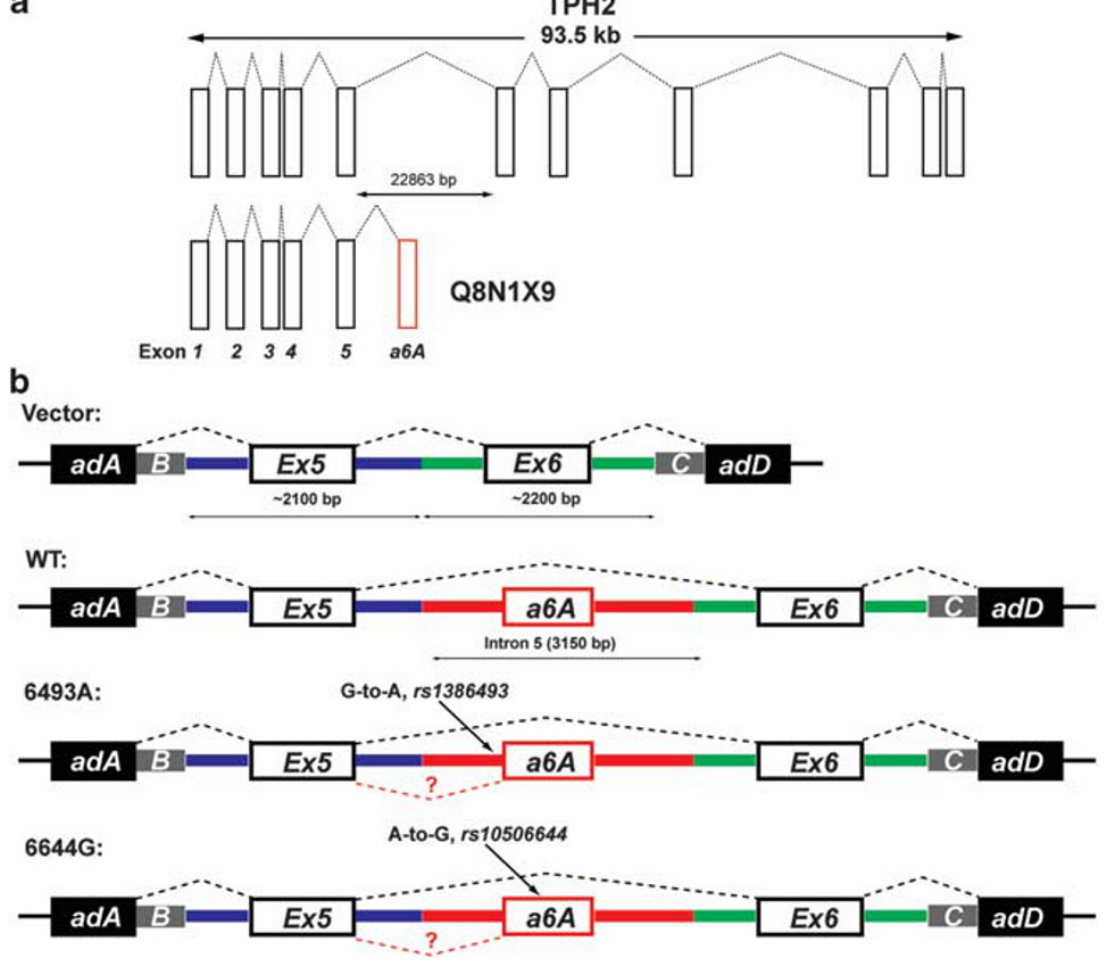

Figure 1 TPH2 genomic DNA and minigene constructs. (a) Full-length TPH2 genomic DNA sequence and its truncated form, Q8N1X9 are shown with open boxes as exons. The red box highlights the alternatively spliced exon a6A in Q8N1X9. (b) Partial TPH2 genomic DNA in minigene constructs. The constitutively active minigene construct consisted of adenovirus exonic sequences (dark boxes adA and adD) and adenovirus intronic sequences (gray boxes B and C).$^{18}$ The vector construct containing TPH2 genomic DNA with exon 5 (Ex5), exon 6 (Ex6) and their respective upstream and downstream intronic sequences (blue and green) is referred to as vector construct. WT construct was generated when TPH2 genomic DNA sequence in intron 5 (red), flanking the alternatively spliced exon a6A, was cloned into vector construct between $5^{\prime}$ - and $3^{\prime}$ intron 5 sequences as shown. Constructs into which G-to-A single-nucleotide polymorphism (SNP) (rs1386493) and A-to-G (SNP rs10506644) substitutions were introduced are designated as 6493A and 6644G constructs, respectively. Dotted lines indicate splicing patterns. Sizes of genomic DNA are illustrated and shown with arrows.

$\sim 93.5 \mathrm{~kb}$ on Chromosome 12q21.1. A truncated form of TPH2 gene spanning only six exons has been previously identified from a human brain cDNA library and deposited as Q8N1X9 (Ensembl: ENST00000266669). ${ }^{16}$ By sequence comparison, we identified that the first five exons of Q8N1X9 were identical to those in TPH2, whereas its sixth exon (exon a6A) was within the $22863 \mathrm{bp}$-long intron 5 of full-length TPH2 gene, and was $11897 \mathrm{bp}$ downstream of exon 5, suggesting Q8N1X9 represents an alternatively spliced form of the $\mathrm{TPH} 2$ gene (Figure 1a).

Minigene constructs using partial TPH2 genomic DNA As constitutive splicing of primary transcript RNA requires both cis- and trans-acting factors, ${ }^{17}$ the existence of Q8N1X9 suggested that mutation(s) in intron 5 and surrounding exon a6A junction might give rise to conditions that compromised the normal splicing of intron 5 leading to abnormal exon 5 and exon a6A recognition. We searched known SNPs in the NCBI database and located two candidate SNPs: rs1386493 (G/A SNP) that was $154 \mathrm{bp}$ upstream of exon a6A and rs10506644 (A/G SNP) that was within exon a6A. To determine whether these two candidate
SNPs were functional by causing alternative splicing, we used a previously established minigene construct strategy consisting of constitutively active adenovirus exons and introns for splicing and neomycinresistance gene $\left(\mathrm{NeO}^{\mathrm{R}}\right)$ for antibiotic selection. ${ }^{18}$ As the TPH2 gene possesses a $22863 \mathrm{bp}$-long intron 5 , and most of the cis-acting elements for splicing are usually in proximity of exons, ${ }^{17}$ we chose to use partial genomic DNA with $\sim 1000 \mathrm{bp}$ each upstream and downstream of the exons of interest. We thus amplified $\sim 2000$ bp of TPH2 genomic DNA sequences flanking exon 5 and exon 6 , respectively, and then cloned these DNA sequences into the minigene construct to generate a vector construct (Figure 1b), which allowed normal splicing for a transcript containing adenovirus exons, exon 5 and exon 6 (Figures $2 \mathrm{~b}$ and d). We then cloned a 3150-bp TPH2 genomic DNA sequence in intron 5 flanking the alternatively spliced exon a6A into the vector construct (wild-type, WT construct). We subsequently generated mutant constructs at these two particular positions: 6493A construct (G-to-A substitution corresponding to rs1386493) and $6644 \mathrm{G}$ construct (A-to-G substitution corresponding to rs10506644) (Figure 1b). 

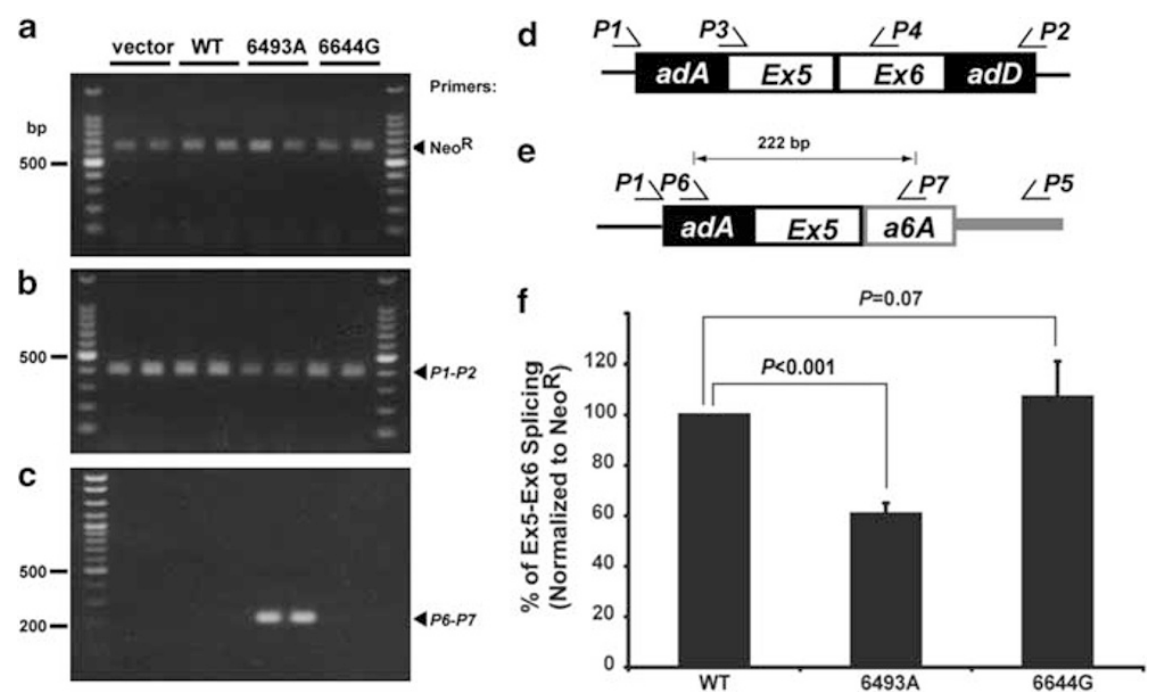

Figure 2 Assessment of the influence of intronic single-nucleotide polymorphisms (SNPs) on TPH2 splicing. (a-c) RT-PCR detected a 397-bp normal spliced transcript (b, d) and a 622-bp $\mathrm{Neo}^{\mathrm{R}}$ transcript (a) as an internal control. Nested PCR using primer set $(P 1-P 5)$ followed by $(P 6-P 7)$ revealed a 222-bp transcript (c) as predicted by alternative splicing of exon a6A (e). All PCR products were confirmed by sequence analysis (data not shown). (f) Real-time RT-PCR to measure normal splicing of intron 6 using primer set $(P 3-P 4)$ and $\mathrm{Neo}^{\mathrm{R}}$ as an internal control indicated a significant decrease in the efficiency of normal splicing only when SNP (rs1386493) was expressed. (All data are presented as means \pm s.d. Statistical significance of all data presented was analyzed by Student's $t$-test; $N=10$.)

SNP (rs1386493), but not (rs10506644) reduced normal splicing efficiency through alternative splicing

We transfected plasmids encoding vector alone, WT, 6493A, 6644G constructs into PC12 cells and generated stable cell lines expressing TPH2 minigene constructs. RT-PCR was then performed using a 622-bp fragment of $\mathrm{Neo}^{\mathrm{R}}$ as internal control (Figure 2a). The normal splicing was detected by PCR using primer set $(P 1-P 2)$ specific for the adenovirus exonic sequences (Figure 2b). The vector construct produced a single, $397 \mathrm{bp}$ PCR product (Figure 2b), which was confirmed by sequence analysis as the normal splicing product (Figure 2d, data not shown). When PC12 cells expressing the minigene constructs encoding WT and mutants (6493A and 6644G) were analyzed, the same single PCR product was shown. However, the normal transcript of $397 \mathrm{bp}$ was reduced when 6493A construct was present (Figure 2b). To determine whether this decrease of normal exon 5-exon 6 transcripts in PC12 cells expressing 6493A was significant, we performed real-time RT-PCR using primer set (P3-P4; Figure 2d) and normalized to $\mathrm{Neo}^{\mathrm{R}}$ level. As shown in Figure 2f, an $\sim 40 \%$ decrease in level of exon 5-exon 6 transcript was detected when 6493A construct was expressed, whereas level of exon 5-exon 6 transcript was not affected in the presence of $6644 \mathrm{G}$ construct as compared with the WT construct. Thus, the decrease of normal splicing efficiency suggested the existence of an alternative spliced transcript. To address this possibility, we first performed RT-PCR using a specific primer located downstream of exon a6A, and carried out nested PCR amplification to identify a 222-bp PCR fragment (Figure 2e) corresponding to the formation of exon 5-exon a6A transcript in PC12 cells expressing 6493A construct (Figure 2c). Therefore, we conclude that SNP (rs1386493) induces an alternatively spliced TPH2 transcript Q8N1X9, and decreases normal intron 5 splicing efficiency.

\section{TPH2-TR is a dominant-negative mutant}

As $Q 8 N 1 X 9$ was isolated from a cDNA library, ${ }^{16}$ a $3^{\prime}$ untranslated region sequence should be present downstream of exon a6A, which is required for mRNA stability. ${ }^{19}$ To test this, we designed a green fluorescent protein (GFP) construct under the CMV promoter in the backbone of a pBluescript vector (pBS-GFP; Figure 3a). In the absence of a downstream $3^{\prime}$-untranslated region, pBS-GFP was unable to express GFP protein (Figure $3 \mathrm{~b}$ ). In contrast, when the 1500-bp downstream sequence of exon a6A (a6A/U) was cloned to generate pBS-GFP-a6A/U, GFP expression was abundantly detected by western blotting (Figure 3b), indicating a6A/U was sufficient to stabilize Q8N1X9 mRNA. We next amplified exon a6A and generated full-length cDNA of Q8N1X9 (TPH2-TR; Figure 4b), with an N-terminal hemagglutinin epitope tag, and co-transfected it alone or along with hemagglutinin-tagged full-length $\mathrm{TPH} 2$ into PC12 cells and determined TPH2 activity by measuring 5-HT production. ${ }^{8,9}$ Western blotting indicated that TPH2-TR was co-expressed with TPH2 (Figure 3c). Whereas TPH2-TR alone in PC12 cells was devoid of enzyme activity, co-expressing full-length TPH2 and increasing amounts of TPH2-TR, indicated that despite being expressed at lower levels, TPH2-TR exerted a dominant-negative effect on TPH2 for 5-HT production (Figure 3d). 
a
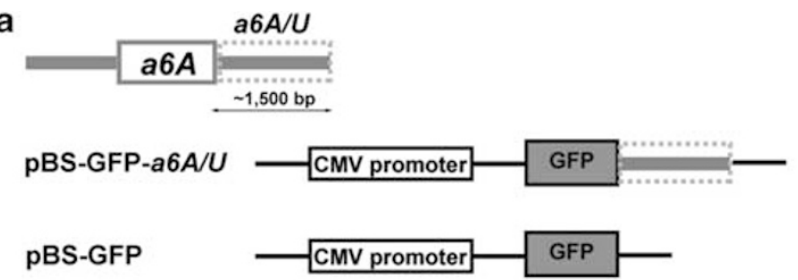

b

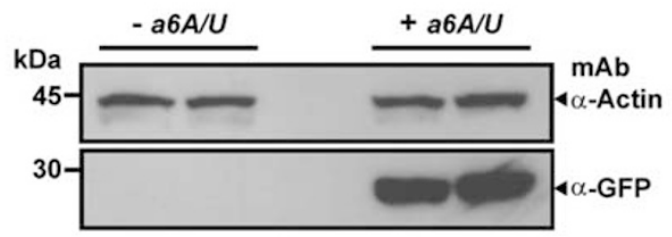

C
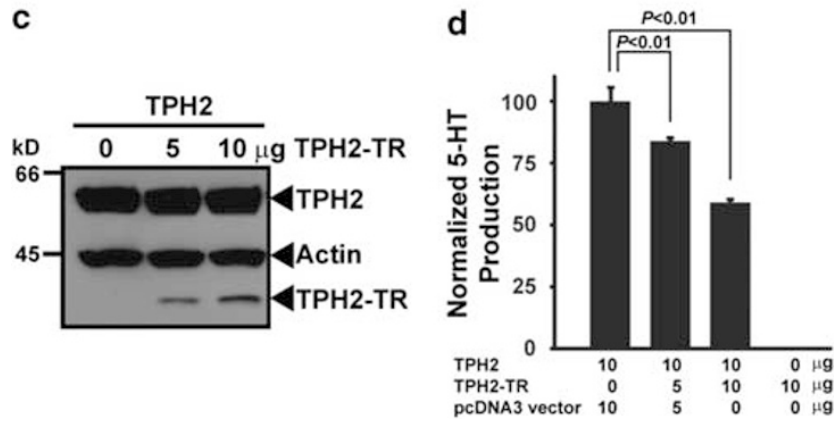

Figure 3 Characterization of genomic elements and Q8N1X9 transcript. (a) A 1500-bp genomic DNA sequence downstream of exon a6A, (a6A/U, gray box) was cloned into a pBluescript vector with a CMV promoter and a green fluorescent protein (GFP) gene as shown. (b) After transfection into HEK293 cells, western blotting indicated that GFP was expressed only in the presence of a6A/U sequences. (c) A plasmid encoding full-length TPH2 was co-transfected with or without a plasmid encoding truncated TPH2-TR into PC12 cells. Products were detected by western blotting for the hemagglutinin (HA) epitope tag using actin as a control (d) 5-HT production was determined by HPLC after normalizing full-length TPH2 expression and using endogenous dopamine as an internal control as described previously. ${ }^{8,9}$ (All data are presented as means \pm s.d. Statistical significance of all data presented was analyzed by Student's $t$-test; $N=3$.) The color reproduction of this figure is available on the html full text version of the manuscript.

\section{Q8N1X9 in human brainstem tissues}

In order to confirm Q8N1X9 mRNA in human, postmortem brainstem tissues were obtained from the brain collection at the University of Mississippi Medical Center. We first developed a restriction fragment length polymorphism analysis for SNP (rs1386493), and genotyped 143 genomic DNA samples (A-allele frequency 0.19) from the brain collection and obtained available brainstem tissue (pons/ medulla) of one wild-type (6493GG), one heterozygous (6493GA) and two homozygous samples (6493AA). We performed RT-PCR using nested PCR amplification with primer set $(P 8-P 5)$ followed by primer set $(P 9-P 10)$ to obtain the full-length $Q 8 N 1 X 9$ transcript (Figure 1a). The 995-bp fragment was detected in the two homozygous 6493AA and the one hetero- a
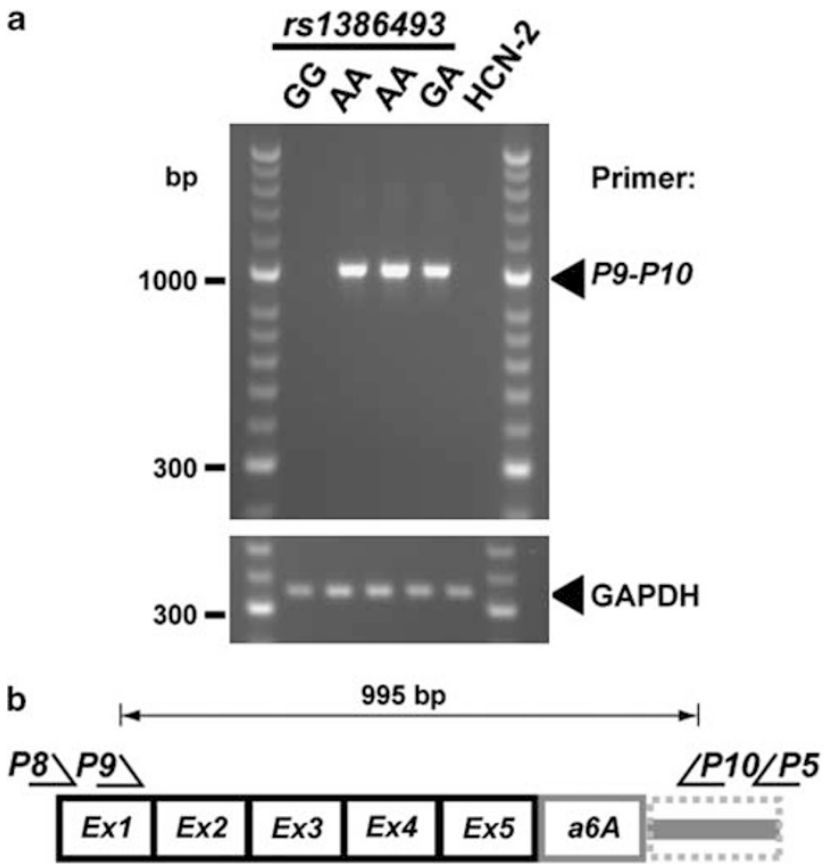

Figure $4 \quad Q 8 N 1 X 9$ in human brainstem tissues. (a) RT-PCR of postmortem brainstem tissues followed by nested PCR analysis. (b) PCR primer sets $(P 8-P 5$ and $P 9-P 10)$ were designed according to predicted Q8N1X9 transcript. RTPCR product from human cortical neuron-derived HCN-2 cell line was used as a negative control.

zygous 6493GA samples (Figure 4) and confirmed by sequence analysis (data not shown), whereas Q8N1X9 transcript was absent in wild-type 6493GG sample. Therefore, Q8N1X9 transcript is expressed in human brainstem tissues carrying the SNP (rs1386493).

\section{SNP (rs1386493) in depression cohorts}

Given the functional significance associated with the A allele of SNP (rs1386493), we hypothesized that it could be associated with the clinical diagnosis of depression. We genotyped the A-allele frequency in Caucasian subjects of the STAR ${ }^{*} \mathrm{D}(N=1084)^{20,21}$ and control $(N=1200)$ cohorts, but found no significant differences $(0.17$ vs 0.18$)$. In addition, a similar distribution of the A-allele frequency (0.21) was found in a set of 99 Caucasian probands derived from multiplex families of the NIMH Center for Genetic Studies Depression Pedigree. ${ }^{22}$ However, further analysis of four families whose probands were homozygous for the A allele revealed 11 of 16 individuals were homozygous for the A allele (Figure 5).

\section{Discussion}

The average vertebrate gene is $\sim 27000 \mathrm{bp}$ long separated by multiple small exons each of 150$300 \mathrm{bp.}^{23}$ It has been estimated that at least $74 \%$ of human genes are alternatively spliced, ${ }^{24}$ and $\sim 15 \%$ of all point mutations causing human genetic disease result from mRNA splicing defects. ${ }^{25}$ This suggests that diverse effects on development, physiology, as 
1174
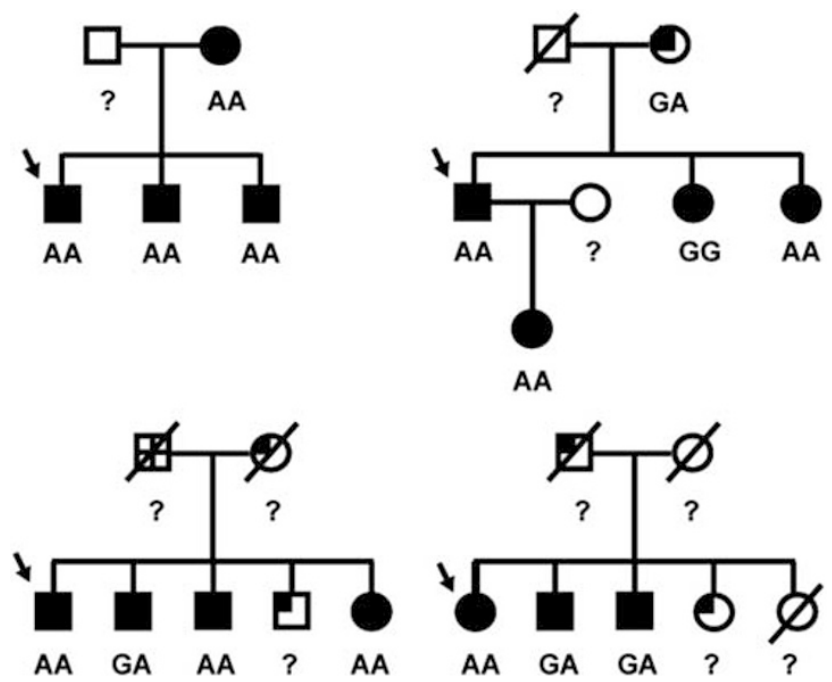

Figure 5 Genotyping of samples from four pedigrees whose probands were homozygous AA in the NIMH Center for Genetic Studies Depression Pedigree. 'AA,' 'GA,' 'GG' indicate homozygous AA, heterozygous GA and wild-type GG for single-nucleotide polymorphism (SNP) (rs1386493), respectively. Arrows show probands where homozygous SNP (rs1386493) was identified. '?' indicates unknown genotypes (missing DNA samples).

well as disease-causing events might be due to aberrant splicing and abnormal protein function. ${ }^{26,27}$ In fact, emerging evidence indicates that splicing defects have an important role in many neurologic diseases. ${ }^{28-30}$ Here, we identify a functional intronic mutation in the human TPH2 gene that generates an alternatively spliced form $Q 8 N 1 X 9$, consisting of the first 5 exons of TPH2 gene plus an additional $145 \mathrm{bp}$ of exon a6A (Figures 1a, 2 and 4).

Our identification of a functional role for the SNP (rs13286493) in alternative splicing is also corroborated by bioinformatic examination of TPH2 intronic sequences. Exon recognition requires not only the traditional $5^{\prime}$-, $3^{\prime}$-splice sites and branch sites, but also both exonic and intronic splicing enhancers and silencers. ${ }^{28}$ A growing family of serine/arginine-rich proteins ${ }^{31}$ have been well characterized for their role as splicing factors through binding to exonic splicing enhancers. Upstream sequences of exon a6A conform to a 'canonical' intron-exon junction, and the ESEfinder tool ${ }^{32}$ predicts that sequences surrounding SNP (rs1386493) can serve as recognition sites for two splicing factors (SF2/ASF and SC35), whereas the A allele would cause reduced binding of these putative splicing factors. Interestingly, SF2/ASF has been previously shown to function as a repressor of downstream exon recognition when its binding site is located in an intron. ${ }^{33}$ Therefore, the accuracy of normal intron 5 splicing could, at least in part, be due to the binding of SF2/ASF, and the A allele could partially remove the inhibitory element thereby causing recognition of exon a6A.

TPH2 consists of an N-terminal regulatory domain, a catalytic domain and a C-terminal tetramerization domain, and belongs to the superfamily of aromatic amino-acid hydroxylases including tyrosine hydroxylase, phenylalanine hydroxylase and TPH1. ${ }^{34}$ As the truncated TPH2-TR retains the entire regulatory domain and a small portion of catalytic domain (Figure 1a), its dominant-negative activity may lie in its interference with the normal function of the regulatory domain in the full-length protein. ${ }^{35,36}$

A number of genetic analyses have indicated association between the TPH2 gene and central nervous system disorders like depression, ${ }^{14}$ bipolar disorder $^{37,38}$ and attention-deficit/hyperactivity disorder. ${ }^{39}$ A functional characterization was carried out for a rare loss-of-function $\mathrm{R} 441 \mathrm{H}$ mutation in an elderly depression cohort whose patients experienced life-long depression, and were resistant to treatment. ${ }^{9}$ Recently, transgenic knock-in mice carrying the equivalent human $\mathrm{R} 441 \mathrm{H}$ mutation were shown to recapitulate the predicted $>80 \%$ decrease in brain 5HT synthesis and to exhibit behavioral abnormalities similar to certain endophenotypes of depression and anxiety. ${ }^{40}$ Similarly, the SNP rs1386493 has been previously studied as a common genetic variant. Zill et $a .^{14}$ identified an A-allele frequency of $19 \%$ in control subjects $(N=265)$, which was similar to that in a depression cohort $(N=300)$. In another study, Haghighi et al. ${ }^{15}$ showed an A-allele frequency of 7.2 and $21.3 \%$ in depression $(N=82)$ and control $(N=80)$, respectively $(P=0.001)$, but the authors concluded that 'the association with SNP (rs1386493) might be spurious' due to a relatively small cohort in the study and somewhat unexpected finding that the mutated allele was more frequent in the control cohort. Haghighi et al. ${ }^{15}$ speculated that variants within this region of the gene might contribute to the generation of the shorten transcript from the TPH2 gene. Our functional characterization, however, reveals a potential mechanism for the pathological function of this common SNP. It will be of great interest for further investigation to ascertain the potential epistatic interaction between this common SNP and genetic variants in genes related to brain 5-HT homeostasis including the 5-HT transporter, the vesicular monoamine transporter 2 (VMAT2), 5-HT receptors as well as other $\mathrm{TPH} 2$ variants.

The identification of another functional SNP (rs1386493) in this study in addition to several other functional variants reported in the TPH2 gene $^{10-12}$ are reminiscent of the characterization of over 400 functional mutations in phenylalanine hydroxylase $(P A H)$ gene, which cause various degrees of hyperphenylalaninemia and its severe symptom, phenylketonuria. ${ }^{41}$ Moreover, a recent study of the TPH2 gene in postmortem brain tissues has identified a number of rare mutations that affect splicing or arise from RNA editing. ${ }^{42}$ Therefore, these data strongly suggest that multiple common or rare functional genetic variants in a single or multiple susceptibility genes could contribute to 5-HT-related psychiatric conditions. ${ }^{13,43-45}$

Major depression is a complex heterogeneous disorder with markedly different clinical profiles 
and responses to drug treatment, ${ }^{1,46-48}$ and may also represent a disorder with different endophenotypes ${ }^{49}$ or with other comorbid psychiatric conditions. ${ }^{50-53}$ Genetic susceptibility, in addition to environmental and biochemical influences, have been extensively studied for the etiology of depression. ${ }^{1}$ However, the existence of both genetic and non-genetic risk factors, as well as limitations in diagnostic criteria, ${ }^{54}$ are major challenges in understanding the molecular mechanisms underlying the symptoms of depression. This SNP (rs1386493) is a relatively common variant (18-20\% prevalence) of the THP2 gene that has been reported in previous studies. ${ }^{14,15}$ However, its relation to depression has been difficult to ascertain. Although the STAR*D cohort represents unrelated individuals diagnosed with depression, the 99 probands genotyped in this study were selected from multiplex families in the NIMH Depression Pedigree, which presumably harbors stronger genetic influences. In fact, in an examination of four families in which the probands were homozygous, 11 of 16 individuals were AA allele carriers (Figure 5). The identification of the homozygous mutant allele in these families raises the possibility that this mutation may contribute to familial forms of depression. As the number of probands from the multiplex families in NIMH Depression Pedigree is too small to achieve significance, further studies with larger cohorts of multiplex families will be needed to determine the relevance of this dominant-negative mutant allele to depression or other psychiatric disorders.

Functional genetic variants are important for our understanding of the pathophysiology of human diseases. Although coding non-synonymous mutations are rare, but relatively easy to characterize, coding synonymous, intronic, as well as promoter and untranslated region variants are more common, but difficult to study. Minigene constructs using partial genomic DNA are useful tools to address the functionalities of these variants by comparing normal gene patterns with those carrying either one or more genetic variants. This is especially helpful for studying psychiatric disorders in which the availability of tissues is limited to postmortem brains. Functional characterization of SNP (rs1386493) and its pathological consequences suggest that the TPH2 gene deserves further attention as a potential risk factor for depression.

\section{Conflict of interest}

The authors declare no conflict of interest.

\section{Acknowledgments}

The authors would like to dedicate this paper to the memory of our esteemed colleague Dr Marcy C. Speer who passed away in 2008. This study was funded in part by the Intramural Research Program of the National Institute of Mental Health, NIH. The content of this publication does not necessarily reflect the views or policies of the DHHS, nor does mention of trade names, commercial products, or organizations imply endorsement by the United States Government. We thank the National Institute of Mental Health (NIMH) Center for Collaborative Genetic Studies on Mental Disorders. Specific acknowledgement is given for $S T A R{ }^{*} D$ research team in performing the clinical study and gathering the DNA samples. We deeply appreciate the assistance of the next-of-kin of the deceased, and gratefully acknowledge the support of Elizabeth K Balraj, MD, and the staff of the Cuyahoga County Coroner's Office, Cleveland, OH, USA, for access to postmortem brain samples. We gratefully acknowledge Lisa Konick and Lesa Dieter and Drs James C Overholser, George Jurjus and Herbert Y Meltzer for psychiatric assessments of the subjects. We also thank Ava Sweeney, Xiuqin Zhang (M.G.C. lab), David Mauger (M.A.G-B. lab), Dhanrajan Tiruchinapalli (Jack Keene laboratory, Duke), Liang Kee Goh, Sharon O'Neill and King Shung Khoo (Duke-NUS) for their laboratory technical assistance and advice. We also acknowledge the advice and helpful discussion of Drs Allison Ashley-Koch (Duke), John Rush and Steve Rosen (Duke-NUS). This work was supported in part by National Institutes of Health Grants MH079201 (M.G.C), MH060451 (K.R.R.K.), MH067996 (C.A.S.), RR017701 (C.A.S., G.R.), Singapore National Medical Research Council Translational and Clinical Research Program NMRC/ TCR/003-GMS/2008 (X.Z and M.G.C.), Singapore Ministry of Education T208A3126 (X.Z.), NARSAD Distinguished Investigator Award (M.G.C.), NARSAD Young Investigator Award (X.Z.), The Lennon Family Foundation (M.G.C.), the Canadian research funds from CIHR, CPRF and AstraZeneca (P.R.A.).

\section{References}

1 Lesch KP. Gene-environment interaction and the genetics of depression. J Psychiatry Neurosci 2004; 29: 174-184.

2 Bobb AJ, Castellanos FX, Addington AM, Rapoport JL. Molecular genetic studies of ADHD: 1991 to 2004. Am J Med Genet B Neuropsychiatr Genet 2005; 132: 109-125.

3 Miyamoto S, LaMantia AS, Duncan GE, Sullivan P, Gilmore JH, Lieberman JA. Recent advances in the neurobiology of schizophrenia. Mol Interv 2003; 3: 27-39.

4 Arango V, Huang YY, Underwood MD, Mann JJ. Genetics of the serotonergic system in suicidal behavior. J Psychiatr Res 2003; 37: 375-386.

5 Lesch KP, Bengel D, Heils A, Sabol SZ, Greenberg BD, Petri S et al. Association of anxiety-related traits with a polymorphism in the serotonin transporter gene regulatory region. Science 1996; 274: 1527-1531.

6 Pezawas L, Meyer-Lindenberg A, Drabant EM, Verchinski BA, Munoz KE, Kolachana BS et al. 5-HTTLPR polymorphism impacts human cingulate-amygdala interactions: a genetic susceptibility mechanism for depression. Nat Neurosci 2005; 8: 828-834.

7 Walther DJ, Peter JU, Bashammakh S, Hortnagl H, Voits M, Fink H et al. Synthesis of serotonin by a second tryptophan hydroxylase isoform. Science 2003; 299: 76

8 Zhang X, Beaulieu JM, Sotnikova TD, Gainetdinov RR, Caron MG. Tryptophan hydroxylase-2 controls brain serotonin synthesis. Science 2004; 305: 217.

9 Zhang X, Gainetdinov RR, Beaulieu JM, Sotnikova TD, Burch LH, Williams RB et al. Loss-of-function mutation in tryptophan hydroxylase-2 identified in unipolar major depression. Neuron 2005; 45: 11-16. 
10 Scheuch K, Lautenschlager M, Grohmann M, Stahlberg S, Kirchheiner J, Zill $\mathrm{P}$ et al. Characterization of a functional promoter polymorphism of the human tryptophan hydroxylase 2 gene in serotonergic raphe neurons. Biol Psychiatry 2007; 62: 1288-1294.

11 Chen GL, Vallender EJ, Miller GM. Functional characterization of the human TPH2 5 ' regulatory region: untranslated region and polymorphisms modulate gene expression in vitro. Hum Genet 2008; 122: 645-657.

12 Cichon S, Winge I, Mattheisen M, Georgi A, Karpushova A, Freudenberg $\mathrm{J}$ et al. Brain-specific tryptophan hydroxylase 2 (TPH2): a functional Pro206Ser substitution and variation in the $5^{\prime}$-region are associated with bipolar affective disorder. Hum Mol Genet 2008; 17: 87-97.

13 Zhang X, Beaulieu JM, Gainetdinov RR, Caron MG. Functional polymorphisms of the brain serotonin synthesizing enzyme tryptophan hydroxylase-2. Cell Mol Life Sci 2006; 63: 6-11.

14 Zill P, Baghai TC, Zwanzger P, Schule C, Eser D, Rupprecht R et al. SNP and haplotype analysis of a novel tryptophan hydroxylase isoform (TPH2) gene provide evidence for association with major depression. Mol Psychiatry 2004; 9: 1030-1036.

15 Haghighi F, Bach-Mizrachi H, Huang YY, Arango V, Shi S, Dwork AJ et al. Genetic architecture of the human tryptophan hydroxylase 2 Gene: existence of neural isoforms and relevance for major depression. Mol Psychiatry 2008; 13: 813-820.

16 Ota T, Suzuki Y, Nishikawa T, Otsuki T, Sugiyama T, Irie R et al. Complete sequencing and characterization of 21,243 full-length human cDNAs. Nat Genet 2004; 36: 40-45.

17 Black DL. Mechanisms of alternative pre-messenger RNA splicing. Annu Rev Biochem 2003; 72: 291-336.

18 Carstens RP, McKeehan WL, Garcia-Blanco MA. An intronic sequence element mediates both activation and repression of rat fibroblast growth factor receptor 2 pre-mRNA splicing. Mol Cell Biol 1998; 18: 2205-2217.

19 Mazumder B, Seshadri V, Fox PL. Translational control by the $3^{\prime}-$ UTR: the ends specify the means. Trends Biochem Sci 2003; 28: 91-98.

20 Rush AJ, Trivedi M, Fava M. Depression, IV: STAR ${ }^{*}$ D treatment trial for depression. Am J Psychiatry 2003; 160: 237.

21 McMahon FJ, Buervenich S, Charney D, Lipsky R, Rush AJ, Wilson $\mathrm{AF}$ et al. Variation in the gene encoding the serotonin $2 \mathrm{~A}$ receptor is associated with outcome of antidepressant treatment. Am J Hum Genet 2006; 78: 804-814.

22 Levinson DF, Zubenko GS, Crowe RR, DePaulo RJ, Scheftner WS, Weissman MM et al. Genetics of recurrent early-onset depression (GenRED): design and preliminary clinical characteristics of a repository sample for genetic linkage studies. Am J Med Genet B Neuropsychiatr Genet 2003; 119: 118-130.

23 Zhang MQ. Statistical features of human exons and their flanking regions. Hum Mol Genet 1998; 7: 919-932.

24 Johnson JM, Castle J, Garrett-Engele P, Kan Z, Loerch PM, Armour CD et al. Genome-wide survey of human alternative premRNA splicing with exon junction microarrays. Science 2003; 302: 2141-2144.

25 Krawczak M, Reiss J, Cooper DN. The mutational spectrum of single base-pair substitutions in mRNA splice junctions of human genes: causes and consequences. Hum Genet 1992; 90: 41-54.

26 Faustino NA, Cooper TA. Pre-mRNA splicing and human disease. Genes Dev 2003; 17: 419-437.

27 Garcia-Blanco MA, Baraniak AP, Lasda EL. Alternative splicing in disease and therapy. Nat Biotechnol 2004; 22: 535-546.

28 Cartegni L, Chew SL, Krainer AR. Listening to silence and understanding nonsense: exonic mutations that affect splicing. Nat Rev Genet 2002; 3: 285-298.

29 Licatalosi DD, Darnell RB. Splicing regulation in neurologic disease. Neuron 2006; 52: 93-101.

$30 \mathrm{Li}$ Q, Lee JA, Black DL. Neuronal regulation of alternative premRNA splicing. Nat Rev Neurosci 2007; 8: 819-831.

$31 \mathrm{Fu} \mathrm{XD}$, Maniatis T. Isolation of a complementary DNA that encodes the mammalian splicing factor SC35. Science 1992; 256: 535-538.

32 Cartegni L, Wang J, Zhu Z, Zhang MQ, Krainer AR. ESEfinder: a web resource to identify exonic splicing enhancers. Nucleic Acids Res 2003; 31: 3568-3571.
33 Dauksaite V, Akusjarvi G. Human splicing factor ASF/SF2 encodes for a repressor domain required for its inhibitory activity on pre-mRNA splicing. J Biol Chem 2002; 277: 12579-12586.

34 Fitzpatrick PF. Tetrahydropterin-dependent amino acid hydroxylases. Annu Rev Biochem 1999; 68: 355-381.

35 Carkaci-Salli N, Flanagan JM, Martz MK, Salli U, Walther DJ, Bader $\mathrm{M}$ et al. Functional domains of human tryptophan hydroxylase 2 (hTPH2). J Biol Chem 2006; 281: 28105-28112.

36 Murphy KL, Zhang X, Gainetdinov RR, Beaulieu JM, Caron MG. A regulatory domain in the $\mathrm{N}$ terminus of tryptophan hydroxylase 2 controls enzyme expression. J Biol Chem 2008; 283: 13216-13224.

37 Harvey M, Gagne B, Labbe M, Barden N. Polymorphisms in the neuronal isoform of tryptophan hydroxylase 2 are associated with bipolar disorder in French Canadian pedigrees. Psychiatr Genet 2007; 17: 17-22.

38 Lopez VA, Detera-Wadleigh S, Cardona I, Kassem L, McMahon FJ. Nested association between genetic variation in tryptophan hydroxylase II, bipolar affective disorder, and suicide attempts. Biol Psychiatry 2007; 61: 181-186.

39 McKinney J, Johansson S, Halmoy A, Dramsdahl M, Winge I, Knappskog PM et al. A loss-of-function mutation in tryptophan hydroxylase 2 segregating with attention-deficit/hyperactivity disorder. Mol Psychiatry 2008; 13: 365-367.

40 Beaulieu JM, Zhang X, Rodriguiz RM, Sotnikova TD, Cools MJ, Wetsel WC et al. Role of GSK3 beta in behavioral abnormalities induced by serotonin deficiency. Proc Natl Acad Sci USA 2008; 105: 1333-1338.

41 Pey AL, Desviat LR, Gamez A, Ugarte M, Perez B. Phenylketonuria: genotype-phenotype correlations based on expression analysis of structural and functional mutations in PAH. Hum Mutat 2003; 21: 370-378.

42 Grohmann M, Hammer P, Walther M, Paulmann N, Buttner A, Eisenmenger $\mathrm{W}$ et al. Alternative splicing and extensive RNA editing of human TPH2 transcripts. PLoS One 2010; 5: e8956.

43 Wright A, Charlesworth B, Rudan I, Carothers A, Campbell H. A polygenic basis for late-onset disease. Trends Genet 2003; 19: 97-106.

44 Goldstein DB. Common genetic variation and human traits. N Engl J Med 2009; 360: 1696-1698.

45 Frazer KA, Murray SS, Schork NJ, Topol EJ. Human genetic variation and its contribution to complex traits. Nat Rev Genet 2009; 10: 241-251.

46 Malhotra AK, Murphy Jr GM, Kennedy JL. Pharmacogenetics of psychotropic drug response. Am J Psychiatry 2004; 161: 780-796.

47 Peters EJ, Slager SL, McGrath PJ, Knowles JA, Hamilton SP. Investigation of serotonin-related genes in antidepressant response. Mol Psychiatry 2004; 9: 879-889.

48 March JS, Vitiello B. Clinical messages from the treatment for adolescents with depression study (TADS). Am J Psychiatry 2009; 166: $1118-1123$

49 Hasler G, Drevets WC, Manji HK, Charney DS. Discovering endophenotypes for major depression. Neuropsychopharmacology 2004; 29: 1765-1781.

50 Oquendo MA, Friend JM, Halberstam B, Brodsky BS, Burke AK, Grunebaum MF et al. Association of comorbid posttraumatic stress disorder and major depression with greater risk for suicidal behavior. Am J Psychiatry 2003; 160: 580-582.

51 Fineberg NA, Fourie H, Gale TM, Sivakumaran T. Comorbid depression in obsessive compulsive disorder (OCD): symptomatic differences to major depressive disorder. J Affect Disord 2005; 87: 327-330.

52 Sher L. Serotonin and suicidal behavior in patients with comorbid depression and alcoholism. Am J Addict 2006; 15: 198.

53 Moffitt TE, Harrington H, Caspi A, Kim-Cohen J, Goldberg D, Gregory AM et al. Depression and generalized anxiety disorder: cumulative and sequential comorbidity in a birth cohort followed prospectively to age 32 years. Arch Gen Psychiatry 2007; 64: 651-660.

54 Krishnan KR. Psychiatric disease in the genomic era: rational approach. Mol Psychiatry 2005; 10: 978-984.

(c) This work is licensed under the Creative Commons Attribution-NonCommercialNo Derivative Works 3.0 Unported License. To view a copy of this license, visit http://creativecommons. org/licenses/by-nc-nd/3.0/ 